\title{
Strategy to Prevent Terrorist Network in Recruitment and Selection of New Employees at Pertamina Hulu Energy Nunukan Company (PHENC)
}

\author{
Muhammad Roy Urich Kusumawardhana* \\ Human Resource Management \\ Sekolah Tinggi Manajemen PPM \\ Jakarta, Indonesia \\ *mkusumaw16@gmail.com
}

\author{
Ningky Sasanti Munir \\ Strategic Management \\ Sekolah Tinggi Manajemen PPM \\ Jakarta, Indonesia \\ ningkymunir@gmail.com
}

\begin{abstract}
The threat of terrorism in Indonesia is quite a challenge nowadays due to the phenomenon that some terrorist actors are actually part of company employees. The process of selecting and recruiting new employees is very strategic in preventing the entry of terrorism networks into a business organization in Indonesia. PHENC as one of the largest oil and gas of state owned companies in Indonesia, namely PT Pertamina (Persero) which is being one of the operational targets of terrorists, this was obtained from the ex-combatants interviewed in this study. Terrorist teams have data and images of pipelines, wells and oil and gas refineries throughout Indonesia. The data obtained from the direct interviews with the combatants is their ability to recruit candidates from young people to older people from academia to religious and business circles. With the ability to recruit each year they can produce 50 people with the ability to attack that can save larger victims and attacks on strategic objects with the ultimate goal of making the country improve the results of these attacks. Therefore, PHENC as a national vital object needs to have a strategy to prevent the terrorism network in the recruitment and selection of new employees. This research uses applied research using qualitative methods and narrative research. Narrative is all about collecting and telling a stories (in detail). Qualitative data in this study were collected by written interview method with several representatives of PHENC management. The analysis technique used is descriptive analysis. The analysis result shows that currently PHENC has not conducted a Background Check (BC) in the recruitment and selection process of new employees. Besides that, recruitment and selection was found as security threat in risk register of PHENC. The design of strategy to prevent the terrorism network in the recruitment and selection of new employees, it is proposed to consist of three parts. The first part is for new permanent employees of PHENC. The second part is intended for new outsourcing employees and the last part is the implementation of an integrated security management system. The design of the strategy can be implemented through eight steps.
\end{abstract}

Keywords-terrorism, recruitment and selection, risk management, securiry management system

\section{INTRODUCTION}

The threat of terrorism in Indonesia is a tough challenge today with the phenomenon that some terrorists are part of the company's employees. In the event of a terrorist attack on May 16, 2018, there was suspected State Owned Company's employees who became funders of the terrorist attack operation plan to the Police Head Quarter of Riau Province that have been successfully stopped by the Police. Other incidents are terrorist attacks to Hotel JW Marriott and Ritz Carlton on Friday July $17^{\text {th }} 2009$, where one of the actors is an employee who has been a florist in that hotel for approximately 4 years in the Hotel [1]. Both terrorism events indicate that every company should be alert and ensure that all of employees exclude from terrorism network.

Seeing the above phenomena, the handling of terrorism in Indonesia is the authority of the National Agency for Counter Terrorism (NACT) as well as the Indonesian Police/Military. Based on information submitted through direct interview to the Protection Director of NACT, Brigadier General (Pol) Herwan Chaedar, NACT has conducted deradicalisation program as an effort to prevent the expansion of terrorist network, assisting ex-terrorists to return to daily life in the society, and to take repressive action to groups of active cells with a raid scenario. However, it should be noticed that the NACT has not yet had a special formula to prevent terrorists to be part of state owned enterprise (SOE) employees. Currently, preventive action of NACT in the form of programs such as increasing national values through training, workshops, seminars to reduce the impact of terrorist network in today's youth

PT Pertamina Hulu Energi Nunukan Company (PHENC) is a subsidiary of PT Pertamina (Persero) which has been acquired from Anadarko, a United States company. In addition, PT Pertamina (Persero) has been designated as a national vital object by the Ministry of Energy and Mineral Resources. This is based on consideration in case of interference with PT Pertamina, will result in disruption of Indonesian oil and gas supply. With such status and operational considerations, a systemic security strategy is required, including in preventing the terrorist networks enter the company.

PHENC as part of the national vital object of PT. Pertamina Hulu Energi (PHE) operates in the area of Nunukan, North Kalimantan, which is the border region of Indonesia-Malaysia. According to Ustadz Ali Fauzy as the chairman of the Peace Circle Foundation, which is a foundation for former combatants at the direct interview in Tenggulun Village, Solokuro Sub-district, Lamongan, East Java, stated that the border area was also often used as terrorist traffic by without passports to enter and exit to and from Malaysia, Thailand and Philippines. In addition, Ustadz Ali said that terrorist networks 
can recruit 50 new people to become active and trained terrorists within a year. The training was conducted in several countries such as Afghanistan, Moro, Malaysia, and Indonesia. During the training period, they were trained to preach, strategic military, read maps, use and make weapons (Lethal Weapon/bombs), tactics of war and field engineering. The former napiter were also taught in the use of bombs for the battlefield, with the changing of unexploded aircraft bombs, putting up mine bombs, and renewed bombs to become attack weapons. The knowledge of bombs ranges from kitchen seasoning, C4, Ammonium nitrate, to TNT. In addition, they were given the knowledge to calculate the specific bomb composition to destroy the building, destructing the enemy's defences until mass killing. To launch the action, the terrorists can work in groups or move themselves (lone wolves).

According to Ustadz Ali, the terrorist network already has data related to all pipes, wells, and oil and gas refineries in Indonesia that can be used as an object of attack. The data is obtained from insider network into a company or government agency. This is because terrorists are clever in camouflage, so it is relatively difficult to detect. They can easy to enter become one of the employees through the process of recruitment and selection which is not strictly. One of the objectives is to have access to facilitate their terror actions. It could be possible occur in PHENC. If the terrorist network enters PHENC through recruitment and selection of new hires, it will pose a risk that can have a significant impact on the company's continuity. Thus, recruitment and new employee selection activities are a strategic thing to protect PHENC from the entering terrorist networks into the company's internal. For that, PHENC needs to have a strategy for preventing terrorist networks from recruitment and selection of new employees. The urgency of strategy to prevent the terrorist networks is illustrated by figure 1 below.

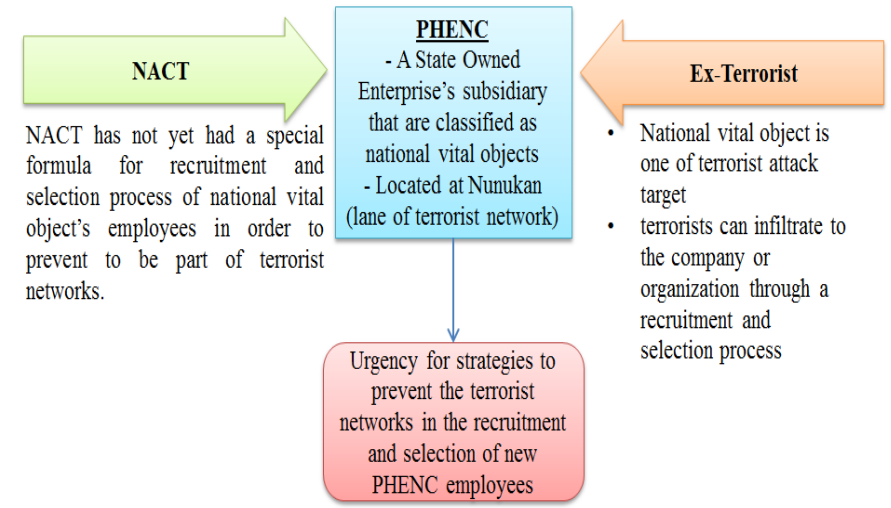

Fig. 1. The urgency for strategies to prevent the terrorist networks in the recruitment and selection of nrw phnc employees.

\section{LITERATURE REVIEW}

\section{A. Terrorism Theory}

Terrorism is the premeditated, systematic threat or use of violence by subnational groups to attain a political, religious, or ideological objective through intimidation of a large audience [2]. Doz and Williamson stated that in some cases, terrorist networks took over characteristics of the meta-national organization that can learn locally and source centrally [3]. Managerial perceptions and responses regarding terrorism appear to differ across organizations, and depend on various factors [4]. Czinkota et al explained that organizational preparedness is important to prevent terrorism. It can be provided by guideline of security measures, anti-terrorism technology, and other useful approach for ensuring vital organizational system. Besides that, Czinkota, et al also stated that management should examine company-wide risk and interdependencies, perform risk-reduction planning and restructure risk. In addition, there is important role by developing integrated risk management models that account for terrorism within corporate strategy [5].

Firmansyah in his research entitled "efforts to tackle terrorism in Indonesia" states that in order to prevent terrorism, the government has taken several steps [6]. The first step is to increase security, control of firearms, transportation systems, public facilities, and communication systems. The second step is surveillance of explosives and chemicals assembled into bombs. The third step is to tighten border controls and entrances. The fourth step is community surveillance that leads to acts of terror. The fifth step is intensification of self-help activities. Finally, conducting an anti-terrorism campaign through the mass media.

\section{B. Human Resource Risk Management}

In the implementation of the corporate's risk management process, each party should consider stakeholders as well as conditions affecting the organization, both internal and external conditions [7]. A corporate risk assessment is an important step in the evaluation of risk to determine its mitigation priorities. Corporate risk mapping is principally drafting a risk based on certain groups so that management can identify the character of each risk and assign appropriate action to each risk as a risk mitigation effort. Human Resource (HR) risk is part of an operational risk with the risk of productivity, technology, innovation, system, process. HR risk is very strategic in the operational level of the company; this is because the company's $\mathrm{HR}$ is the operator of the company to achieve its objectives. If the risk of HR is not managed properly and comprehensive, then there will be operational disruption of the company that impacts the company's losses.

The recruitment process is part of the list of human resources that has been identified by the company as part of the corporate-level operational risk. Mitigating recruitment risk and selection is carried out on a level starting from the input, process, and output of the recruitment and selection process.

\section{Recruitment and Selection Process}

The development of recruitment and selection strategies is crucial to securing one of the most valuable assets in the organization to pursue competing excellence. According to William and Dobson, human resources general strategy, as well as recruitment and selection strategies in particular, are coherent and aligned with current and future business strategies, will contribute significantly to organizational performance [8]. 
The preparation of HR strategies is also influenced by the characteristics of business strategy used. According to Miles and Snow, there are three typologies of ananisasi org strategy, namely: Defender, prospector, and Analyser [9].

The recruitment and selection process by Pergamon Flexible Learning can be divided into 3 parts, namely planning, recruitment and selection [10]. The planning phase includes analysis on the urgency of recruitment, doing job analysis, and making job description, Competency profile and person specification. In the future, the recruitment stage consists of determining which method is most suitable for recruitment, how it is interested in applying and marketing the job vacancy. In the last step, the selection, starting from sorting incoming applications, conducting interviews, making decisions and bidding and contacting the Applicant reference. 2:

Thus, the analytical framework of this study is as in figure

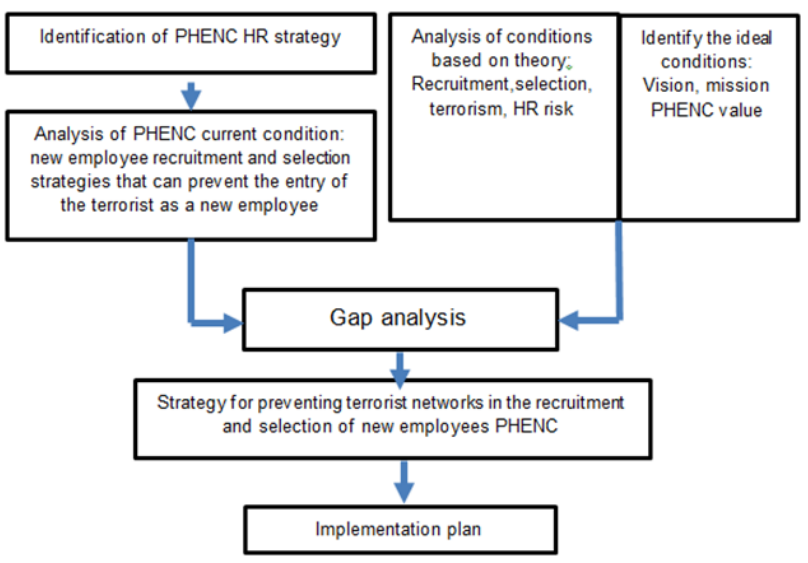

Fig. 2. Analytical framework.

\section{Methodology}

This research is an applied research type. According to Sekaran and Bougie, applied research is a study conducted in certain settings with specific objectives to resolve problems that exist in the situation [11]. Currently, PT Pertamina Hulu Energi Nunukan Company (PHENC) needs to have a strategy for preventing terrorist networks from recruiting and selection of new employees as described in the background section of the research. This type of applied research is a descriptive study, which is research describing variables in an interesting situation for researchers. This research focuses on the actual problem solving PHENC as it is at the time of research. In addition, this research serves to solve practical problems of science development, namely human resource management, risk management and security system management.

This research is done qualitatively which does not use statistical data and is narrative. Narrative means this research is detailed on the situation in the research object. Therefore, it can be said that this research uses qualitative data. Sekaran and Bougi state that qualitative data is data that cannot be immediately quantifiable unless encoded and categorized in several ways. This qualitative Data is obtained through interviews with the Department of Human Resources (HR) and employees who have participated in the selection set to become PHENC employees. Besides that, direct interview conducted with ex-combatant or terrorist, namely Ustadz Ali Fauzy as the chairman of the Peace Circle Foundation to obtain data regarding terrorism network in Indonesia and Brigadier General (Pol) Herwan Chaedar as National Agency for Counter Terrorism (NACT) to collect information regarding how the government strategy to prevent terrorism network.

The data used in this study consists of two types, namely primary data and secondary data. Primary Data was collected through written interviews with nine of PHENC representatives from the Human Capital, Security Coordinator, IT Coordinator, Formalities Specialist, Senior Geologist, General Facility Management, and HSE. The secondary data is collected through document study from SOP recruitment and PHENC selection and company website.

In general, the data processing techniques in this study use descriptive analysis. Corporate vision, mission, and values Data are processed with descriptive analysis to know the business strategy that the company will do to achieve the goals of PHENC. After that, the results of written interviews, SOP document, and the recruitment and selection in the analysis in a descriptive way to determine the condition of current recruitment and selection strategies that can prevent terrorist networks from entering as new employees. The theory of terrorism, HR risk management, recruiting and selection strategies and Processes are learned to find out how the ideal recruitment and selection strategy is designated to prevent and counteract terrorist networks into PHENC as well as aligned with corporate strategies. The validity of written interviews from respondents was tested by the triangulation method by comparing the correctness of the respondent to the other respondents.

Gap analysis is conducted to determine which dimensions of strategy are not yet appropriate and need improvement. The results of the gap analysis are further used to draft the strategy of preventing terrorist network locals in the recruitment and proposed selection for PHENC. Lastly, the proposed recruitment and selection strategy is designed to develop a proposed activity or program related to the recruitment strategy and PHENC selection.

\section{RESULTS AND DISCUSSION}

\section{A. Identification of Human Resouces Strategy}

To determine the typology of the strategy, according to Miles and Snow, there are five aspects that need to be considered, including: product-market strategy, research and development, production, and marketing. Firstly, it is reviewed from the product -market strategy, PHENC product is included in the stable product, meaning only specific in the form of oil and gas. In addition, the target market is also clear, namely all people or institution that use oil and gas. Therefore, based on the product-market strategy aspect, PHENC's business strategy is skewed into the defender typology.

The second and third aspects of business strategy determination can be seen from the production aspect as well as research and development. In this aspect, PHENC 
emphasizes on efficiency in all lines, optimization of production and budget of investment costs, as well as project supervision. It is listed in the direction of corporate strategy. This type of strategy is identical with the typology of defender which in the aspect of research and development, the company leads to product improvement. In addition, the production process has an emphasis on efficiency and process engineering. Of the twelve strategies mentioned, seven business strategies lead to the characteristics of the defender, namely: efficiency in all lines, increasing oil and gas production, increased lifting, monetization of gases, acceleration of place into service, zero impairment, and continuous Improvement.

The fourth aspect to define a typology of business strategy is in the marketing aspect. In this aspect, PHENC marketing is limited only in terms of sales. Therefore, referring to the theory of Miles and Snow, the stronger that PHENC business strategy is confounded on the defender strategy.

Based on the explanation above, it can be concluded that PHENC's business strategy has a defender typology. Therefore, the defender strategy became the choice of PHENC to achieve the vision of the company, which is to become "World Class Petroleum and Natural Gas Sector" with PHENC content to carry out the management of operations and portfolios of oil and gas and energy in a professional and high profit power that provides added value for stakeholders.

The company's business strategy has implications in the HR strategies used. In terms of recruitment, selection and placement, it is identical with the make or internal recruitment strategy to meet the needs of its employees at the upper level. According to Miles and Snow, HR strategy in terms of recruitment, selection, and placement, in the defender Strategy Company will emphasize the "make" strategy. Few of recruitment was conducted for top-level employees. Recruitment and selection are only in general to meet the needs of employees at the entry level.

Since PHENC is the acquisition company of Anadarco, most of the management is an innate employee of the Anadarco. These employees are the result of "make" or a form of company before the acquisition of the internal permanent officer PHENC. As for the existing employee data, outsourcing officer PHENC is the second most employees, which is $43 \%$, after internal employees. Outsourcing Employees are intended for workshop or production. This is most likely due to the use of outsourcing employees, PHENC can reduce operational costs. It is in line with PHENC's business strategy that emphasizes efficiency on each of the lines.

\section{B. Analysis of Current Recruitment and Selection Strategy}

The recruitment and selection of PHENC new employees are categorized into three groups, namely: employees of fresh graduate, experienced hired and outsourcing which are mostly innate contractors. Employee outsourcing on PHENC is dominated by officers in the field who came from the contractor. By using outsourcing employees, PHENC can suppress labour costs. However, on the other hand, the outsourcing officers posed several challenges for PHENC. First, employee engagement is relatively low resulting in low loyalty. Secondly, outsourcing employees can provide less optimal performance if strict surveillance is not performed.

In addition, in order to meet the needs of its internal officers, PHENC is open to accept potential new employees from external. Thus, any party can follow the recruitment process and selection as a new officer PHENC. However, the open recruitment process is ideally equipped with appropriate screening process to produce new employees recruited according to the order of corporate values. Currently the new PHENC Screening process is limited to the completeness of administration.

In the perspective of terrorism, terrorism is a group or selfsustaining movement to fight for ideological, notion through the imposition of wills by committing terror to the public in order to obtain support and justification collectively. The result of the analysis above judging by the perception of terrorism theory, the comprehensive and collective step-up of the Congress is required of all stakeholders involved in the PHENC environment. In addition, the need for the involvement of the community around the location of the company operates the dialogue to prevent the entry of terrorist networks in the environment, the same effort is made to establish a common awareness in the company's internal to be aware of each other to see the extreme behavioural changes that lead to the righteous attitude itself, intolerant and full of hatred. This is because such attitudes will be easy to make a terror effort against the company for the benefit of a group or personal.

Terrorism is very opposed to one of the values adopted by PHENC, which is clean. Clean value means the management of the company professionally, avoiding conflicts of interest, does not tolerate bribery, uphold trust and integrity. Guiding the principles of good corporate governance. Based on theory, terrorism can be interpreted as an attempt to gain or retain power or control by means of intimidation. This can lead to conflicts of interest and does not uphold trust and integrity. Thus, terrorism should be prevented and denied from PHENC because it does not conform to the value of its values.

Related to the entry prevention strategy of terrorist networks, PHENC has not yet had its mechanism and system. Governments as authorities prevent and mitigate terrorists through NACT, military, and police also have no specific strategy to prevent terrorist networks from entering into institutions or organisations that manage national vital objects. In fact, based on the theory, one of the objects that target terrorism actors are vital objects.

The recruitment and selection process became one of the strategic aspects of the company, including for PHENC. This is because the process can be utilized by irresponsible parties, including terrorists, to infiltrate the internal company with the aim to do chaos. Thus, PHENC which has a national vital object status and is located in Nunukan (terrorist exchange lane between countries), needs to have a recruitment and selection strategy that can ensure that the prospective employees have an undeviant ideology and free from terrorist networks. Based on written interviews, PHENC employees have realized that terrorist networks are a threat that can cause harm to the company. For that, they assess the need for human resource filters such as the background check process. This is in the case 
of preventive efforts and early detection of terrorist networks. In addition, PTHENC employees also assess the need for SOP which prevents the entry of terrorist networks as new employees. Thus, it can be concluded that the employee of PHENC has had an awareness of terrorist threats. However, PHENC has not had a good security management system related to the prevention and countermeasures of terrorist networks. During this time, the management of PHENC Security Systems focuses solely on the prevention of theft measures.

In general, the process of recruitment and PHENC selection today has been in line with the recruitment and selection theories according to Snell, Morris and Bohlander. Snell, Morris and Bohlander stated that in the recruitment and selection process, there are at least three phases consisting of planning, recruitment and selection [12]. Based on organizational governance recruitment of PHENC, Planning phase is called "fulfilment planning needs of worker's procurement". The core of the planning stage is job analysis, and makes a job description, Competency profile and person specification. In PHENC, job Analysis started by collecting the data from each function manager regarding the needs of employees and strategic staff for the needs of the following year. Furthermore, the data is submitted to Human Capital Manager to continue to the General Manager until the director through RJPP process. At this stage, each function manager must fill out the employee needs form. The form already has detailed data on job positions and specifications as well as qualified prospective employees.

Step of Recruitment in PHENC is called a "prospective job search (Talent Sourcing)". To perform such activities, PHENC works closely with the external media appointed by the company through its hiring method. The hiring method is implemented integrated with media options such as mass media (advertising), website E-Recruitment, cooperation program with the school, and executive search. From such data, it can be underlined that open recruitment of new employee must be accompanied by a good screening process. Thus, there must be tools that ensure that external parties recruited as new employees are in accordance with the order of corporate values. Similarly attributed to terrorism on the Nunukan lane, new employee candidates must be ensured not related to terrorist networks. The external recruitment of PHENC consists of two types, namely fresh graduate and experience hired.

Based on the theories referring to Snell, Morris and Bohlander, the selection stage begins with the screening process. As for PHENC screening process IN THE form of administrative selection in terms of GPA value, TOEFL and college accreditation for fresh graduate. Meanwhile, the administrative requirements for experience hired are only the minimum period of relevant experience and English proficiency of the TOEFL/TOEIC equivalent.

According to Snell et al, the second stage in the selection is interviews. This is different from what PHENC did to choose the psychology test and the English language as a stage after the first screening. PHENC Put the interview process at the psychological test and English level. The interview method used by PHENC is an interview panel consisting of related functions, the People Development Committee (PDC) and the Human Capital Talent Management (HCTM) function. In the interview, there are six competencies assessed, including: knowledge, skill, attitude and others (KSAO); technical skills; communication and teamwork; initiatives and contributions; self-development and development of others and leadership (only for leader positions). Of these six competencies, the aspect of KSAO has the highest weight of 4 compared to the five other aspects that have only weight of 3 .

Next Stage selection according to Snell, Morris and Bohlander is post interview screening. This step can be conducted by reference check and background check (BC). However, PHENC performs this stage in the form of reference check. It is only for the experience hired while the fresh graduate is not there. It is certainly a notes for PHENC. As explained in chapter I that PHENC is located in the area of Nunukan which is an inter-state terrorist exchange lane. Therefore, the BC process is important for PHENC to ensure that the prospective new hires have the same value-setting as the company. This becomes the gap that writers find from the selection process done by PHENC. However, based on information obtained by the authors through a written interview with a PHENC employee, the background check process was conducted when PHENC was under the Anadarko Offshore Holding Company (AOHC). However, after the acquisition of PT Pertamina Hulu Energi (PHE), the background check process was eliminated. In fact, the background check process is important to ensure that potential new officers of PHENC are not involved with criminal activities, including terrorism. For that, if the PHENC wants to prevent the inclusion of terrorist networks from entering the company, the background check process needs to be reapplied.

Another gap related to the prevention of terrorist networks in recruitment and selection of new officers is the absence of the requirements of Police Clearance Certificate (PCC). Whereas PCC can be an early filter as an attempt to prevent terrorist networks from entering as a new officer PHENC. This is because by theory, acts of terrorism can be categorized as criminal acts. Therefore, PCC's requirements have been a good prefix in the process of preventing terrorist network location in the selection of new officers of PHENC. However, PHENC has not been able to create a mechanism used to monitor the inclusion of terrorist networks on prospective new hires.

PHENC performs the process of pre-Employment test using psycho test methods and health tests. It is already in line with the recruitment and selection theory whereby PHENC has been running a pre-employment test. Psycho test is only one of several methods that can be done to test potential new employees in relation to knowledge, skills, attitude and Other characteristics (KSAO) that they have.

Based on the overall set of selections, PHENC has not had a validity test. In fact, the validity test is important enough to evaluate whether the employee selection process is already effective and efficient or not. In addition, the decision making method in the selection used by PHENC uses statistical approaches. This is characterized by the standard weight in each competency assessed during the interview. 
The recruitment and selection process described above applies only to PHENC's permanent personnel. The recruitment and employee selection of outsourcing are managed by the company's working partners. Currently, Labour supply procurement for outsourcing Employees only based on contracts agreed between PHENC and the partners. There has been no special mechanism to ensure that outsourcing officers are being used free of terrorism networks. It is a record for PHENC to ensure that outsourcing officers working in PHENC are free from the terrorism network. Therefore, necessary mechanisms and systems are clear to ensure that all new officers who enter the PHENC, both permanent officers, contract officers, and outsourcing officers in accordance with the competencies required by PHENC to achieve the company's objectives and free from the intrusion of terrorism network. Nevertheless, PHENC in a procedure can be said to already have an attempt to prevent the terrorist network from entering as a new employee outsourcing. It is seen from the procedure of making a work partner Badge that requires the completeness of Police Clearance Certificate document (PCC) and special research of new employees. However, for the time being, it is only limited to the necessity of fulfilling the requirements of the QHSSE department.

\section{Analysis of Risk Management in Recruitment and Selection}

Human Resource (HR) Risk is a very strategic thing. This is due to the risk of human resources having a significant impact, especially regarding the recruitment and selection process of new employees who are exposed to terrorist networks and potentially damaging the company from within. To cope with this, a mitigation effort is required by implementing a security management system integrated and integrated by all stakeholders. HR risk mapping in the company's risk profile should consider the entry aspects of terrorist networks into the company as employees, whether permanent, contracts or contractor employees who have access to areas that have sensitive assets can interfere with the operation.

In PHENC's risk registers, the risks in recruitment and selection have not mentioned the intrusion of terrorist networks as new employees. Although based on written interviews that have been done, employees of PTHENC agreed that there is potential entry of terrorist network through recruitment and selection of new employees. In addition, in PHENC Risk registers, the risk of recruitment and selection is classified into low-level risk. It is visible from the green colour listed in the PHENC Risk Register. In fact, in the event of a terrorist act committed by terrorists who infiltrate as PHENC will have a very significant impact on the company.

Mitigation or risk treatment of recruitment and selection written in the register of risk in the form of background check. However, based on written interviews, it has not been conducted again.

\section{Gap Analysis Summary}

After conducting analysis of the current and PHENC recruitment conditions in the event of preventing and counteracting the terrorist network as a new employee by comparing it with terrorism theories, recruitment and selection strategies, and HR risk management, the following is a summary of the gaps that have been identified:

TABLE I. SUMMARY OF GAP ANALYSIS

\begin{tabular}{|c|c|}
\hline Theory & Gap \\
\hline \multirow{3}{*}{ Terrorism } & $\begin{array}{l}\text { The Government has not yet had a formulation } \\
\text { to prevent terrorist networks from entering } \\
\text { into institutions or companies that manage } \\
\text { national vital objects }\end{array}$ \\
\hline & $\begin{array}{l}\text { Organizational preparedness is important to } \\
\text { prevent terrorism nevertheless PHENC } \\
\text { currently does not have particular strategy to } \\
\text { prevent terrorism }\end{array}$ \\
\hline & $\begin{array}{l}\text { No Police Clearence Certificate requirements } \\
\text { in the selection that can prevent terrorist } \\
\text { networks from entering the company as new } \\
\text { employees }\end{array}$ \\
\hline \multirow{3}{*}{$\begin{array}{l}\text { Recruitment and } \\
\text { selection Strategies }\end{array}$} & $\begin{array}{l}\text { No Post-Interview Screening in the form of } \\
\text { background check }\end{array}$ \\
\hline & $\begin{array}{l}\text { No validity test to test the effectiveness of the } \\
\text { selection process }\end{array}$ \\
\hline & $\begin{array}{l}\text { No system and mechanisms to guarantee new } \\
\text { outsourcing employees free from terrorism } \\
\text { network }\end{array}$ \\
\hline \multirow{2}{*}{$\begin{array}{ll}\text { HR } & \text { Risk } \\
\text { Management } & \end{array}$} & $\begin{array}{l}\text { Not mentioning terrorist network in the risk of } \\
\text { recruitment and selection }\end{array}$ \\
\hline & $\begin{array}{l}\text { Mitigation of background check as the } \\
\text { treatment of recruitment risk and selection in } \\
\text { the risk register is not implemented }\end{array}$ \\
\hline
\end{tabular}

The gaps in table 1 become input in designing of the strategy to prevent terrorist networks from the recruitment and selection of new employee in PHENC. In the case of terrorism, National Agency for Counter Terrorism (NATC) has not yet had a formulation to prevent terrorist networks from entering into institutions or companies that manage national vital objects. In addition, there has been no requirement of Police Clearance Certificate (PCC) in the selection that can prevent terrorist networks from entering the company as a new employee of PHENC. Though terrorism is included into criminal actions so that the presence of PCC can be an initial filter in the prevention of terrorist networks.

In terms of recruitment and selection strategies, the gaps that occur are the absence of the background check process. The second gap is that there is no validity test to test the effectiveness of the selection process. Lastly, the absence of systems and mechanisms to ensure new outsourcing employees are freed from the terrorism network.

As for the side of HR risk management, the PHENC risk registers have not mentioned terrorist networks in the risk of recruitment and selection. In addition, the mitigation written on the risk register in the form of background check as the handling of recruitment risk and the selection of the risk register is not running. Those gaps will be input to create a strategy.

\section{E. Strategy Design}

Based on the results of the analysis attributed to the theory and ideal conditions of PHENC which refers to the vision of the mission and the company values, compiled several strategies to block the terrorist network in recruitment and 
selection of new employees. Concept of strategy design to prevent the entry of terrorist networks in PHENC is as in figure 3:
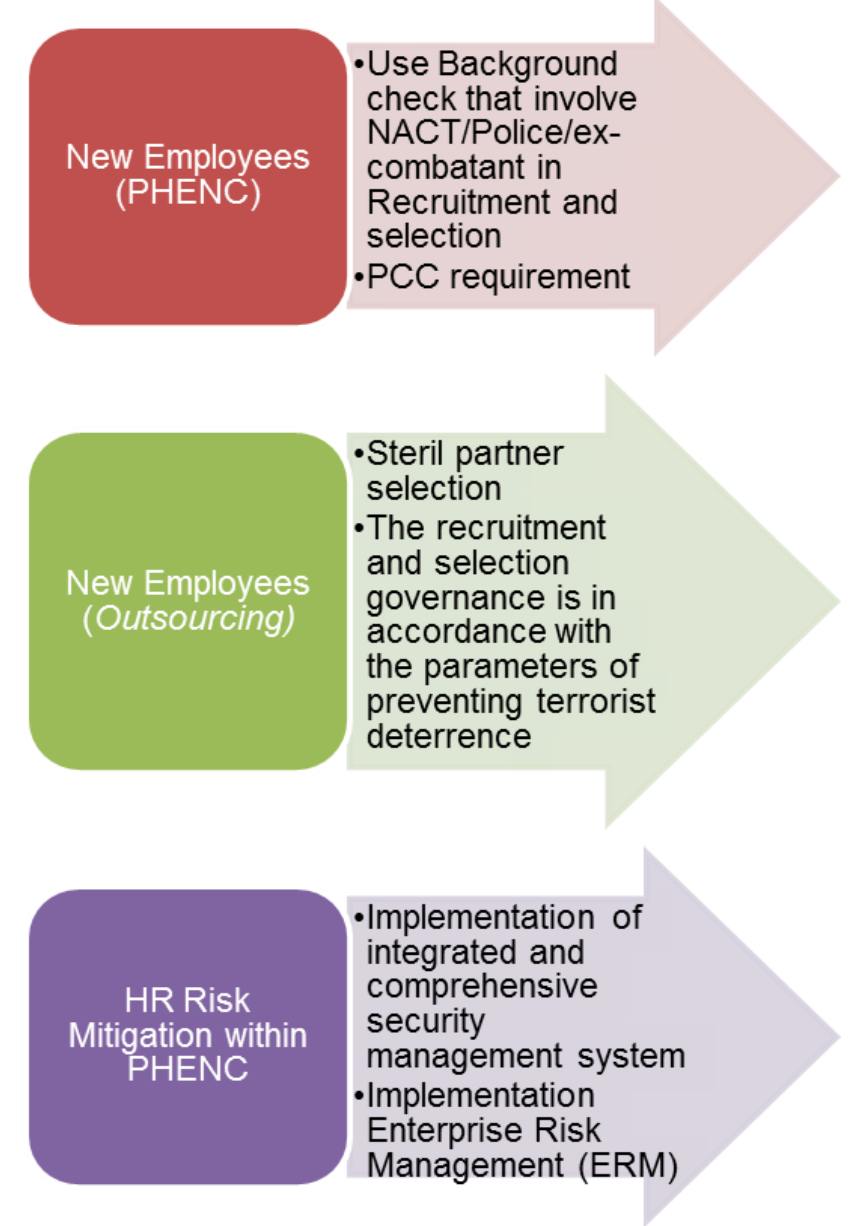

Fig. 3. Design of stategy to prevent terrorism network in recruitment ans selection.

In general, the strategy for preventing terrorist network in recruitment and selection of new employees on PHENC is divided into three parts. First part is for recruitment and selection of new permanent employees of PHENC. The most important effort to prevent and resist the existence of background check involving National Agency for Counter Terrorism (NACT) /Police/former combatant. This is because these three parties have a database related to the list of names involved in terrorist network activities. In addition, PCC requirements are required as an initial filter to prevent the inclusion of terrorist networks as new employees of PHENC.

The recruitment and selection process begins with planning. This phase includes analysis of needs based on Human Resource Planning. After that, conducted job analysis (job analysis), competency profile and person specification against each job that will be carried out recruitment and selection. The second stage is recruitment that can be sourced from internal and external. Job vacancy information at this stage of recruitment must be as clear as possible in accordance with the specifications specified at the time of planning. The proposed recruitment strategy is that recruitment should be able to lead applicants to self-selection. This is done to facilitate the selection process.

The proposed stage of the new officer selection PHENC was to add the process of background check and Police Clearance Certificate (PCC) requirements that had to be completed by potential new employees. The selection phase is initiated by screening administrative requirements and PCC. For Fresh graduate, the requirements of the administrator are the value of GPA, TOEFL, and accreditation of universities. As for the experience hired, the terms of the relevant experience period and the English proficiency of TOEFL or TOEIC equivalent. To anticipate the inclusion of terrorist networks, PCC needs to be a requirement that must be completed by potential new employees. Afterwards, the selection is continued with a background check which can involve competent authorities. In the background check process, the main indicator is that the candidate is not involved in a criminal offense by reviewing the social media of the candidate with the relevant consent. Because from social media can be seen how the daily life of the candidate's new employees.

Selection process of new employee must use background check (BC) involving the relevant authorities, starting from the use of Police Clearance Certificate (PCC) from Baintelkam POLRI, to involve the National Agency for Counter Terrorism (NACT) and former combatants to provide a more accurate and up-to-date input on the candidate profile of new prospective employees of PHENC, especially for areas that have access to sensitive assets to operating disorders. The $\mathrm{BC}$ process is comprehensive from family genealogy, friends, neighbours, study venues or other religious activities, financial status when strategic position, legal status, marital status, and other relevant information.

The selection process is conducted in accordance with the procedure and job qualification with regard to security aspects, especially for a position that has access to sensitive assets. The selection is done by live face-to-front interviews to convince candidate gestures to match the job type. The proposed Interview method is the situational interview or Behavioural description interview. With both methods of interviewing, PHENC can explore the understanding or ideology of potential new hires. If using the Situational Interview method, PHENC which acts as an assessor gives a hypothetic occurrence of terrorism and asks the Applicant to respond and give a response to the incident. The second alternative, when using an interview with the Behavioural Description Interview method, Assessor can ask a few questions about the experiences that have been passed by the Applicant and what he did in the experience. The type of question used in this type of interview is encouraging questions.

Lastly, the selection of pre-employment test is to conduct certain tests to know the competence, cognitive, skills, and other things. Form of pre-employment test can be a psycho test skill or skill test, as well as medical check-up. To select Applicants to be received as new officers, PHENC can compare The candidates to one another according to his job qualification in some way in making decisions. The proposed decision-making method is with the statistical approach to keep 
the selection results objectively. Candidate Selection results are still decided by a recruitment committee meeting consisting of $\mathrm{HR}$, user, and recruiter functions. In this selection process can be seen track record and portfolio candidate in accordance with the work that he has made.

To test the validity of the selection, the proposed method is construct validity. This method is an approach to knowing what personality is relevant to a particular type of work and testing the accuracy of the personality test itself. Associated with terrorism, the method is chosen because terrorism relates to a person's personality. Therefore, construct validity is required to evaluate whether the selection method used can counteract terrorism networks or not yet.

As for the recruitment and selection process for new outsourcing employees consists of three stages. The first stage is planning. Planning is carried out by conducting analysis of new employee needs outsourcing based on Human Resource Planning (HRP). The second stage is the selection of partners who have sterile from terrorist networks. For that, PHENC needs to create a database of partners associated with a reliable and sterile work partner. The third stage is to create a recruitment and selection governance that can meet the parameters of preventing terrorists.

The most important thing in the parameter to prevent terrorist catch-up is the Background Check (BC) process. Both permanent officers PHENC and outsourcing employees are obliged through the $\mathrm{BC}$ selection. At the stage of implementation of new employees must go through the recruitment stage from applying to the selection process. At the time of applying for the recruitment process can be done by $\mathrm{BC}$ to the candidate by using the authorities or conducted internally PHENC. The BC process itself is conducted comprehensive ranging from family genealogy, friends, neighbours, study places or other religious activities, financial status when strategic position, legal status, marital status, and other relevant information.

For the Background Check (BC) process must be applied to all candidates, including candidates for contractor officers entering an area that has an asset that is sensitive to interference. For now, the process of $\mathrm{BC}$ should be conducted at the beginning of recruitment as a permanent employee/contract/ labour supply.

The BC process can be conducted independently by PHENC by conducting a check of the social media in accordance with the candidate's agreement. As for the important and strategic position, it is necessary to involve the authorities such as NACT or police which has a database of terrorist networks in Indonesia. Need further research of BC results especially for employees who are on jobsite Nunukan both recruited from Jakarta and Local hired, either permanent/contract or contractor employees. Screening process can be conducted double check when retrieving the pass from the Security Department, this is to guarantee and assure that all our employees do not belong to the terrorist network.

\section{F. Implementation Plan}

Implementation of design pattern to prevent the entry of terrorist network as PHENC employee can be implemented with full awareness of the importance of implementation is consistently implemented, collectively by all stakeholders. The leadership commitment is one of the successful requirements of the implementation of the pattern of preventing the terrorist network, therefore the leadership as a trustee must have a good understanding and awareness of the threat.

The first of step that can be done by PHENC is to assign recruitment and selection SOP. This SOP explains how the standard process of recruitment and selection of PHENC is to prevent and ward off terrorist networks. The Output of this step is the SOP recruitment document and the selection that has been passed by PHENC management. The PIC or the person in charge of the establishment of this SOP is the HR or department of Human Resource (HR).

The second implementation step that PHENC can make is to create a Background Check (BC) checklist. This Checklist should be tailored to the needs of the job type present in PHENC. The Output from this step is a checklist Background Check (BC) document that has been authenticated by PHENC management. The PIC or the person in charge of the determination of this SOP is the HR or department of Human Resource (HR) also Department of Security.

The Background Check (BC) process can be done according to the job specification needs and safety risk level. Background Check (BC) is divided into 3 (three) levels, namely: for business support function, special production control room, and management. All three categories have different Background Check (BC) tiers. Third category of officers consisting of business support function, special production control room, and management is obliged to submit SKCK as condition of selection. This is because terrorism activities are included in criminal acts so Police Clearance Certificate (PCC) is required as an initial filter to ensure that prospective employees are exempt from the activity of terrorism.

Business support functions (consisting of three states: permanent employees, contracts and outsourced) have the lowest level of Background Check (Level 1). This is because the job specification of this group has the lowest risk level among the two other groups because the access to business operations is relatively limited. For that, BC only needs to be conducted in terms of family, friends, social environment, residential environment and social media.

The second category, which is employees for the special production control room (consisting of three states: permanent employees, contracts and outsourced), needs to undergo A relatively more complex (Level 2) Background Check (BC) than employees for business support functions. This is because employees in this category have access to an area that is vital for PHENC business operations. Thus, more profound BC treatment is required, including: family, friends, social environment, social media, socialization, religious learning places, idol, Indonesian ideology comprehension, previous employment reference. 
The last category of management needs to get the most complex Background Check (BC) treatment (Level 3). This is because management is a strategic position in the company's landscape so that it has a high level of risk. Therefore, BC for management consists of: family, friends, social environment, social media, loan data, stock ownership data, Hobby, socializing, religious places of study, Idol, Indonesian ideology comprehension, previous work reference, State Office Wealth Report, and bankruptcy check.

After making a check list background check, further implementation step, namely the third implementation in the form of working with authorities such as National Agency for Counter Terrorism (NACT) or Police of Republic of Indonesia and former combatants (if required). This is to facilitate the background check during the process of selection of new officers PHENC. The Output of this step is a Memorandum of Understanding (MoU) that has been endorsed by the management of PHENC as well as the authorities. The PIC or the person in charge of the determination of this SOP is part of the Security Department.

The fourth implementation step that PHENC can do is to define selection criteria by considering track record verification to ensure that no terrorist network is exposed. This was done to prevent and defile terrorist networks in the process of selection of new staff PHENC. The Output of this step is a document selection criterion that has been passed by PHENC management. The PIC or the person in charge of the establishment of this SOP is the HR or department of Human Resource (HR).

The fifth implementation step that PHENC can do is to renew a HR risks register as part of operational risk being part of a strategic risk. It is to emphasize that the recruitment and selection process is a critical process to ensure that all candidates who come in as new hires, including outsourcing officers, are aligned with the mission vision and the PHENC value. The output of this step is a risk list document which has been ratified by PHENC Management as well as the authorities. The PIC or the person in charge of the determination of the SOP is the department of Risk Management, HR and Security Department.

The sixth implementation step that PHENC can do is to create a sterile work partner database for outsourcing employees. It is to ensure that partners who cooperate with PHENC sterile parties from terrorist networks and have a recruitment and selection governance that meets the parameters of preventing terrorist network. The Output from this step is a work partner database. The PIC or the person in charge of the determination of this SOP is HR department and Security Department.

The seventh implementation step that can be taken by PHENC is implementing an integrated security management system that is to ensure that security risk control is carried out thoroughly. The output of this step is in the form of policies, guidelines, and SOPs for the security management system (SMP). The PIC or the person responsible for establishing this SOP is the Security Department.
The eighth implementation step that PHENC can do is management of the Background Check result database. The output from this step is a database of $\mathrm{BC}$ results records. The PIC or the person in charge of the determination of the SOP is IT Department, HR, and the Security Department.

\section{CONCLUSION}

The conclusion of this research is the answer to the issue set in the introduction. From the results of analysis and discussion has been generated three conclusions. First, The PHENC strategy is defender strategy where the current PHENC employees are mostly innate officers before the acquisition of Anadarko. The recruitment and selection process is initiated by the recruitment process of external parties. The second stage is the screening process by matching the requirements of administration in accordance with the needs of occupational competence and competence of applicants. Further recruitment and selection are continued with the preemployment test in the form of psycho test, English test and health test. After that, the selection stages are followed by conducting interviews, offering, approvals, induction period and trial period. Thus, the recruitment and selection process at PHENC is currently not doing background check (BC). Currently applicants are not required to submit a Police Clearance Certificate (PCC). Additionally, the PHENC selection process does not yet have a validity test to evaluate the effectiveness of the selection process.

Second, the design of recruitment and selection strategy that can prevent and ward off the risk of the entry of terrorist networks into PHENC is generally divided into three parts. The first part is intended for new permanent employees of PHENC by conducting a Background Check involving authorities such as NACT, Police, or ex-combatants and PCC completeness requirements. The second part is for outsourced employees from contractors in the form of selecting sterile partners and having a recruitment and selection governance that is in accordance with the parameters of preventing terrorist deterrence. The third part is the mitigation of HR risk in the recruitment and selection process by implementing an integrated and comprehensive security management system (SMP) and the application of Enterprise Risk Management (ERM) in the PHENC environment.

The plan to implement recruitment strategies and New employee selection that can prevent and resist the risk of terrorist network entry into PHENC consists of nine steps. First is to set recruitment and selection SOP, by adding the Background Check (BC) requirement and SKCK requirements in the recruitment process. The second step is creating BC Checklist tailored to the needs of the job type. The third step is cooperation with the relevant authorities such as NACT/ Police and former combatants (if required). The fourth step is determining selection criteria by considering track record verification to ensure that no terrorist network is exposed. The fifth step is to do the Update risk register especially the HR risk as part of operational risk being a part of strategic risk. The sixth step is to create a sterile working partner database for outsourcing employees. The seventh step is to integrate the security management system in an integrated and integrated 
manner to ensure thorough control of safety risks. The eighth step is managing the Background Check (BC) database.

\section{ACKNOWLEDGMENT}

By implementing a draft strategy to prevent the terrorist networks in recruitment and selection of new employees, the authors suggest that:

- PHENC can map HR risk as a strategic risk with the threat of the inclusion of terrorist networks through its employees.

- PHENC collaborates with NACT/Police to perform Background Check (BC) against all candidates of new employees in accordance WITH the proposed PHENC SOP.

- Implementing an integrated security management system as a pre-emptive, preventive to repressive step to face the threat of inclusion of terrorist networks as new employees of PHENC.

- Immediately implement Background Check to all employees who are permanently status, contracts to outsourcing of the contractor/labour supply. The service can be done independently or with the authorities such as NACT and or police.

- The good database management of BC Recordings, selection, coaching, counselling from all PHENC employees makes it easy to monitor the occurrence of extreme, radical, and intolerant behavioural changes.

- Security management System (SMP) Certification to assure a consistent implementation of SMP, comprehensive and continual. The benefit of certification is that SMP is audited by independent parties so hopefully the result will be more objective and obey the principles.

\section{REFERENCES}

[1] PT Indonesia News Center Ibrohim, dari Florist ke Bomber - nasional www.inilah.com [Online]. Retrieved from: https://m.inilah.com/news/detail/140972/ibrohim-dari-florist-ke-bomber, Accessed on August 16, 2019.

[2] M.R. Czinkota, G. Knight, P.W. Liesch, and J. Steen, "Terrorism and international business: A research agenda," Journal of International Business Studies, vol. 41, no. 5, pp. 826-843, 2010.

[3] Y. Doz, J. Santos, and P. Williamson, From Global to Metational: How Companies Win in The Knowledge Economy. Boston, MA: Harvard Business School Press, 2004.

[4] B. Sullivan-Taylor and D. Wilson, "Risk, uncertainty and strategy: Coping with the threat of global terrorism," In J. Cantwell \& T. Kiyak (Eds), Proceedings of the Annual Meeting of the Academy of International Business, 30 June - 3 July 2008, Milan, Italy. East Lansing, MI: Academy of International Business, 2008.

[5] J. Sheffi, The resilient enterprise: Overcoming vulnerability for competitive advantage. Boston, MA: MIT Press, 2005.

[6] H. Firmansyah, "Upaya Penanggulangan Tindak Pidana Terorisme di Indonesia,” Jurnal UGM, vol. 23, 2011.

[7] B. Djohanputro, Manajemen Risiko Korporat. Jakarta: PPM Manajemen, 2008.

[8] A.P.O. William and P. Dobson, Personnel Selection and Corporate Strategy. Chicester: John Willey, 1997.

[9] M. Miles and C. Snow, Organization Strategy, Structure and Processes. 1984.

[10] E. Elearn, Recruitment and Selection Revised Edition. Oxford: Elsevier, 2008.

[11] U. Sekaran and R. Bougiee, Research methods for business a skillbuilding approach. Chichester: Wiley, 2017.

[12] S. Snell, S. Morris, and G. Bohlander, Managing Human Resources. Canada: Cengage Learning, 2016. 